\title{
Bioaccessibility of heavy metals in soils cannot be predicted by a single model in two adjacent areas
}

\author{
Xiaodong Zhu $\cdot$ Fen Yang $\cdot$ Chaoyang Wei • \\ Tao Liang
}

Received: 16 November 2014 / Accepted: 7 May 2015/Published online: 16 May 2015

(C) Springer Science+Business Media Dordrecht 2015

\begin{abstract}
The objective of this study was to examine whether a single model could be used to predict the bioaccessibility of heavy metals in soils in two adjacent areas and to determine the feasibility of using existing data sets of total metal concentrations and soil property parameters (e.g., $\mathrm{pH}$, total organic carbon, and soil texture) when predicting heavy metal bioaccessibility. A total of 103 topsoil samples were collected from two adjacent areas (Baotou and Bayan Obo). A total of 76 samples were collected from Baotou, and 27 were collected from Bayan Obo. The total and bioaccessible concentrations of arsenic (As), copper $(\mathrm{Cu})$, lead $(\mathrm{Pb})$, and zinc $(\mathrm{Zn})$ were measured following complete composite acid digestion and a simple bioaccessibility extraction test. The average total concentrations of $\mathrm{As}, \mathrm{Cu}, \mathrm{Pb}$, and $\mathrm{Zn}$ were $8.95,27.53,28.40$, and $79.50 \mathrm{mg} / \mathrm{kg}$,
\end{abstract}

X. Zhu $\cdot$ F. Yang $\cdot$ C. Wei $(\bowtie) \cdot$ T. Liang $(\bowtie)$ Key Laboratory of Land Surface Pattern and Simulation, Institute of Geographic Sciences and Natural Resources Research, Beijing 100101, China

e-mail: weicy@igsnrr.ac.cn

T. Liang

e-mail: liangt@igsnrr.ac.cn

X. Zhu $\cdot$ F. Yang

University of the Chinese Academy of Sciences,

Beijing 100049, China respectively, in Baotou and 18.12, 30.75, 38.09, and $87.62 \mathrm{mg} / \mathrm{kg}$ in Bayan Obo. Except for As, these values were similar in both areas. The average bioaccessible heavy metal concentrations (Bio-HMs) for each target HM were also similar. In Baotou, the average Bio-HM values for $\mathrm{As}, \mathrm{Cu}, \mathrm{Pb}$, and $\mathrm{Zn}$ were $1.16,3.76,16.31$, and $16.10 \mathrm{mg} / \mathrm{kg}$, respectively, and $1.26,2.51,14.31$, and $8.68 \mathrm{mg} / \mathrm{kg}$ in Bayan Obo. However, the relative bioaccessibilities for each HM in Baotou were greater than those in Bayan Obo, with mean values for $\mathrm{Pb}, \mathrm{Zn}, \mathrm{Cu}$, and $\mathrm{As}$ of 57, 20, 17 , and $12 \%$, respectively, in Baotou and 40, 11, 9, and $8 \%$ in Bayan Obo. In both areas, prediction models were successfully created using heavy metal concentrations and soil physicochemical parameters; however, models of the same target element differed between the areas, which indicated that a common model for both sites does not exist. Bio-HMs were highly affected by soil properties, which were found to differ between the adjacent areas. In addition, soil properties with large variations played major roles in the predictive models. This study highlights the importance of incorporating physical and chemical parameters that vary greatly when building predictive models of heavy metal bioaccessibility in soil. A similarity in soil properties between areas might be a prerequisite for the creation of a common predictive model for soil Bio-HMs.

Keywords SBET $\cdot$ Soil properties $\cdot$ Predictive model $\cdot$ Heavy metal $\cdot$ Bioaccessibility 


\section{Introduction}

China is becoming rapidly industrialised and urbanised. Heavy metal contamination has become an increasing concern throughout the country, particularly in some mining and smelting areas in Southern China (Hu et al. 2013; Wei and Yang 2010). Elevated levels of heavy metals (HMs), such as arsenic (As), copper $(\mathrm{Cu})$, lead $(\mathrm{Pb})$, and zinc $(\mathrm{Zn})$, in soils near mining areas have been detected (Ettler et al. 2014; Fu and Wei 2013; Wei et al. 2009). The vast distribution of mining and smelting areas and the associated heavy metal contamination are substantial concerns to the Chinese government and communities, particularly because of the risks posed to human health (Zhu 2012).

Human health risk assessments of HM-contaminated soils are usually based on limited site-specific contaminant data and total (or pseudo-total) HM concentrations. However, numerous studies have shown that HM bioaccessibility (Bio-HM), defined as the fraction of HM contaminants that are gastrointestinally soluble and potentially available for absorption, is the major factor influencing human health risks (Caboche et al. 2010; Oomen et al. 2003; Sauvé et al. 2000). Bio-HM depends primarily on HM binding to soil reactive surfaces and is controlled by sorption, complexation, and redox processes. Each of these processes, in turn, is largely controlled by the variability of soil properties, including $\mathrm{pH}$, organic matter, and soil texture (Pelfrene et al. 2011; Rodrigues et al. 2013). This relationship makes it possible to predict the Bio-HMs of soil (Buchter et al. 1989; Ruby et al. 1999).

Many researchers have created predictive models to estimate Bio-HMs from pre-existing data on the total metal concentrations and edaphic soil properties with the goal of eliminating the need for the costly resampling and analysis of soils (Buchter et al. 1989; Rieuwerts et al. 2006). In recent studies, stepwise multiple linear regression models have widely been used to create these predictive models (Römkens et al. 2009), such as that in Eq. (1):

$$
\begin{aligned}
\log [\text { Bio-HM }]= & a+b \times \log [\mathrm{HM}]+(c+\cdots+n) \\
& \times \log (\text { soil property })
\end{aligned}
$$

where [Bio-HM] is the bioaccessible concentration of each HMs in $\mathrm{mg} / \mathrm{kg}$ and " $a, b, c, \ldots, n$ " are the regression coefficients of each soil property (except $\mathrm{pH}$ ) included in the model (Rodrigues et al. 2010).
Römkens et al. (2009) used multiple linear regression to build models to predict available HMs in four sites in Taiwan, China (Römkens et al. 2009). Rieuwerts et al. (2006) found that $\mathrm{pH}$ was a consistent predictor of the extractability of soil metals by reagents (an accepted surrogate for bioavailability) in North Wales (Rieuwerts et al. 2006). Pelfrene et al. $(2011,2012)$ formed predictive models to identify the most significant soil parameters associated with $\mathrm{Cd}$, $\mathrm{Pb}$, and $\mathrm{Zn}$ bioaccessibility in smelter-contaminated agricultural soils and validated these models with parallel data (Pelfrene et al. 2011, 2012). All of the above studies report that the statistical modelling approach was reasonable and that predictions could be applied to assess the human health risks within the studied area.

Although accurate bioavailability prediction models have been created for specific locations, models predictions vary from site to site. In other words, it is typically difficult to apply a model designed for one site to another site. Sites may vary dramatically in soil properties, which greatly limits the feasibility of using one model at two or more different sites.

Therefore, using models to predict Bio-HMs is still a challenge. In this study, HM and soil property data from two adjacent areas (the Baotou and Bayan Obo Districts) were utilised to examine whether a predictive model created for one site could be applied to another and if not, what were the major factors preventing its applicability.

\section{Materials and methods}

Site description

The Baotou-Bayan Obo Iron-REE mining area is located in Inner Mongolia in Northwest China (Drew et al. 1990). The research area consisted of the Bayan Obo Mining District and the Baotou mineral processing and iron smelting plants, which are $200 \mathrm{~km}$ apart. Bayan Obo is a multi-metal iron and REE mine and covers a total area of $328 \mathrm{~km}^{2}$. The open pit mine has been exploited for iron and REE for 55 years. A tailing dam was constructed in 1959 to receive the tailings from the mineral processing plant (Fig. 1). The dam has a north-to-south length of $3.5 \mathrm{~km}$, an east-to-west width of $3.2 \mathrm{~km}$, and a circular length of $11.5 \mathrm{~km}$. The dam covers an area of $12 \mathrm{~km}^{2}$ and contains 9.3 million 
tons of Iron-REE tailings. Because of strong winds and a lack of vegetation, the dam produces serious dust contamination. This inland area has an arid climate, with low temperature and low precipitation.

Topsoil sampling

The sampling sites were arranged in a circle around the smelting centre in Baotou and around the mining centre in Bayan Obo, with total areas of 1400 and $670 \mathrm{~km}^{2}$, respectively (Fig. 1). At each site, five $25-\mathrm{cm}$ topsoil sub-samples from a sampling area of $5 \mathrm{~m} \times 5 \mathrm{~m}$ were collected and combined to form a composite sample. Soil samples were air-dried, and stones and plant debris were removed. Samples were then crushed and passed through a 2-mm nylon sieve. The $\mathrm{pH}$ was measured in a 1 to 2.5 soil to water suspension and was measured using a $\mathrm{pH}$ meter. Organic matter content (TOM) was analysed using the
Walkley-Black method (Nelson and Sommers 1982). Soil grain size was determined through laser diffraction analysis (Mastersizer 2000, Malvern, UK).

Total concentration and bioaccessibility of heavy metals

Sub-samples with grain sizes of less than $250 \mu \mathrm{m}$ were obtained using an ultracentrifugal mill. To determine $\mathrm{HM}$ concentrations, a portion of the sub-sample was weighed and digested with $\mathrm{HNO}_{3}-\mathrm{HClO}_{4}-\mathrm{HF}$ at $120{ }^{\circ} \mathrm{C}$ on an electric hot plate. The total concentrations of $\mathrm{As}, \mathrm{Cu}, \mathrm{Pb}$, and $\mathrm{Zn}$ in the samples were measured in the digested solution using inductively coupled plasma atomic emission spectroscopy (ICPOES, PE, USA).

A simple bioaccessibility extraction test (SBET) (Drexler and Brattin 2007; Juhasz et al. 2007; Kim et al. 2002; Madrid et al. 2008) was used to assess
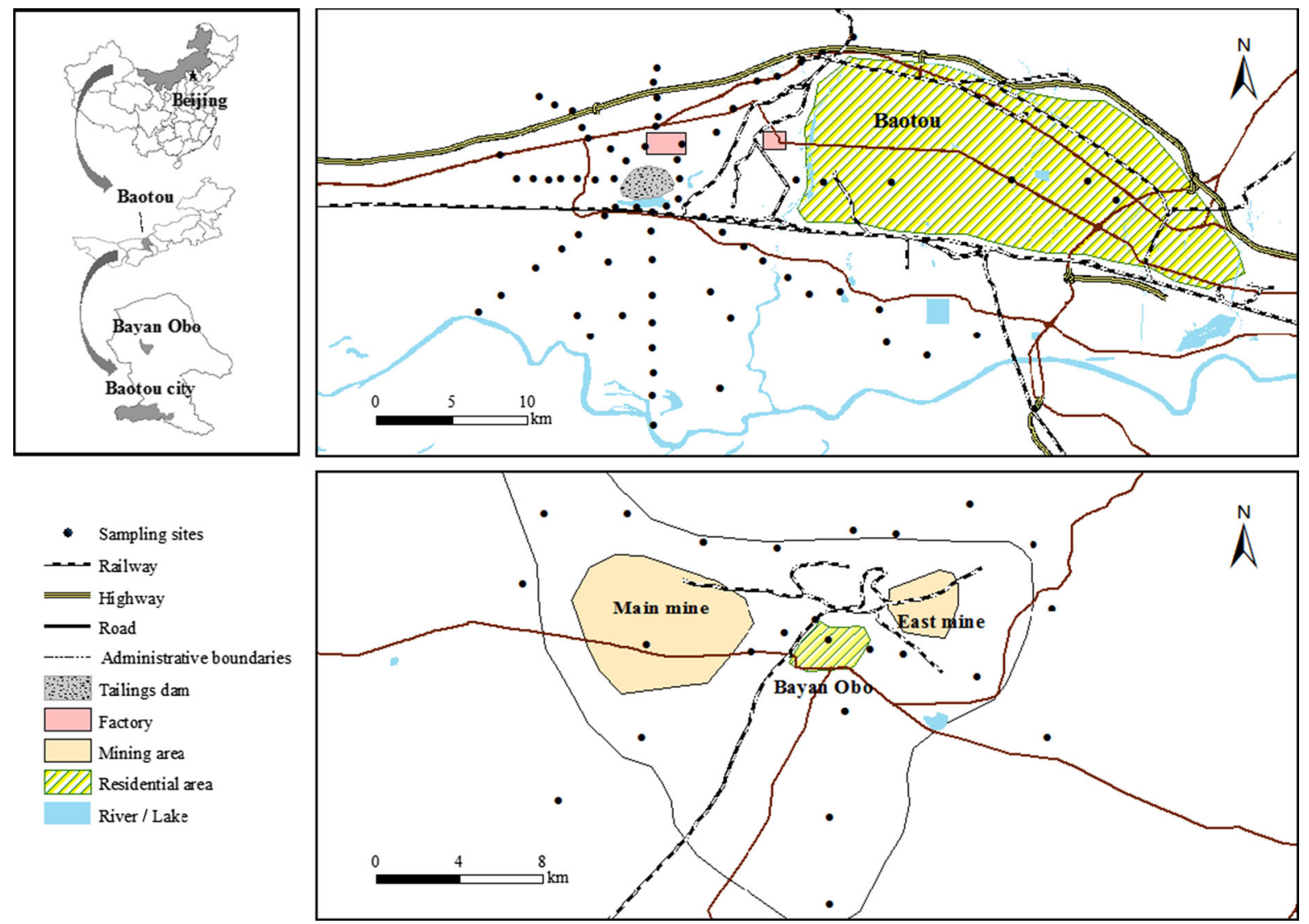

Fig. 1 Location of study area and sampling sites 
the bioaccessibility of $\mathrm{As}, \mathrm{Cu}, \mathrm{Pb}$, and $\mathrm{Zn}$. Briefly, $50 \mathrm{~mL}$ of the $0.4 \mathrm{M}$ glycine extraction solution was added to $0.5 \mathrm{~g}$ of sieved $(<250 \mu \mathrm{m}$ fraction) air-dried soil material in $100 \mathrm{~mL}$ polythene centrifuge tubes. The tubes were shaken end-over-end at $37{ }^{\circ} \mathrm{C}$ for $1 \mathrm{~h}$ at $30 \mathrm{rpm}$. To ensure that all $\mathrm{pH}$ values were within 0.5 units of the starting $\mathrm{pH}(1.5)$, the $\mathrm{pH}$ of a portion of the unfiltered extraction fluid was measured. The mixtures were centrifuged at $3000 \mathrm{rpm}$ for $10 \mathrm{~min}$ after shaking, and the extracted suspension was filtered with a $0.45-\mu \mathrm{m}$ cellulose acetate disc filter. Each sample was analysed in duplicate. Blanks and reference soils materials (GW07412a) were used in each test batch to verify the accuracy of the analysis. Bio-HMs determination was the same as that described above for total HM concentrations (Rieuwerts et al. 2006).

Statistical analysis

SPSS 20.0 for Windows was used to statistically analyse the data. Pearson tests were used to reveal the relationships of various factors, including total HM, Bio-HMs, and soil property parameters. Stepwise regression analysis was used to build predictive models of Bio-HM concentrations. All variables (except $\mathrm{pH}$ ) were log-transformed because of their log-normal distributions (Rodrigues et al. 2013).

\section{Results}

Physical and chemical properties of soils

The $\mathrm{pH}$ values of the soils in Baotou-Bayan Obo areas were mildly to moderately alkaline, with the soil $\mathrm{pH}$ in Baotou slightly higher than that in Bayan Obo. TOM concentrations did not differ between Baotou and Bayan Obo. Grain size analysis revealed differences in soil texture between the two areas. The percentage of sand in Baotou was $63.77 \%$, which was greater than that in Bayan Obo (48.81\%). The silt and clay percentages in Baotou were 32.87 and $3.36 \%$, respectively, which were less than the corresponding percentages in Bayan Obo (42.82 and $8.37 \%$ ). In addition, the standard deviations (SD), coefficients of variation $(\mathrm{CV})$, and ranges of soil properties in Baotou were larger than those in Bayan Obo, with the exception of clay (Table 1).
Total HM concentrations and absolute and relative HM bioaccessibility

The average total concentrations of $\mathrm{As}, \mathrm{Cu}, \mathrm{Pb}$, and $\mathrm{Zn}$ were $8.95,27.53,28.40$, and $79.50 \mathrm{mg} / \mathrm{kg}$, respectively, in Baotou and 18.12, 30.75, 38.09, and $87.62 \mathrm{mg} / \mathrm{kg}$ in Bayan Obo (Table 1). Although Baotou and Bayan Obo differ in industrial activities, as the former is a centre of mineral processing and iron smelting and the latter is mining, the heavy metal concentrations of soils did not significantly differ between the sites (with the exception of As, which was lower in Baotou than in Bayan Obo) (Table 1). The average bioaccessible concentrations (Bio-HMs) of $\mathrm{As}, \mathrm{Cu}, \mathrm{Pb}$, and $\mathrm{Zn}$ were $1.16,3.76,16.31$, and $16.10 \mathrm{mg} / \mathrm{kg}$, respectively, in Baotou and 1.26, 2.51, 14.31, and $8.68 \mathrm{mg} / \mathrm{kg}$ in Bayan Obo. Bio-HMs did not significantly differ between the areas, with the exception of the bioaccessibility of $\mathrm{Cu}$ (Table 1). However, relative bioaccessibility, defined as the percentage of bioaccessible HM to total HM concentrations, differed between the areas; for all of the HMs examined, there were higher relative bioaccessibility values in Baotou than in Bayan Obo. $\mathrm{Pb}$ demonstrated the highest relative bioaccessibility, followed by $\mathrm{Zn}$, $\mathrm{Cu}$, and $\mathrm{As}$. The average relative bioaccessibilities of $\mathrm{Pb}, \mathrm{Zn}, \mathrm{Cu}$, and $\mathrm{As}$ in Baotou were 57, 20, 17, and $12 \%$, respectively, whereas those in Bayan Obo were 40, 11, 9, and $8 \%$ (Table 1). The difference in relative Bio-HMs between Baotou and Bayan Obo indicated that soil property variation influenced the concentrations of Bio-HMs. Significant correlations were found between the total and bioaccessible concentrations of all the HMs in both study areas (except for $\mathrm{Cu}$ in Baotou and $\mathrm{As}$ in Bayan Obo) (Figs. 2, 3).

\section{Prediction models}

Separate predictive models were made for Baotou and Bayan Obo using stepwise multiple linear regressions to model the four HMs (Table 2). At both sites, the accuracy of the bioaccessibility prediction models (as estimated by their $\mathrm{R}^{2}$ values) was ranked as follows: $\mathrm{Pb}>\mathrm{Zn}>\mathrm{As}>\mathrm{Cu}$ (except for As in Bayan Obo). Both HM concentrations and soil property parameters were used to create these models; however, each model included site-specific soil property parameters (Table 2 ). In general, all the 


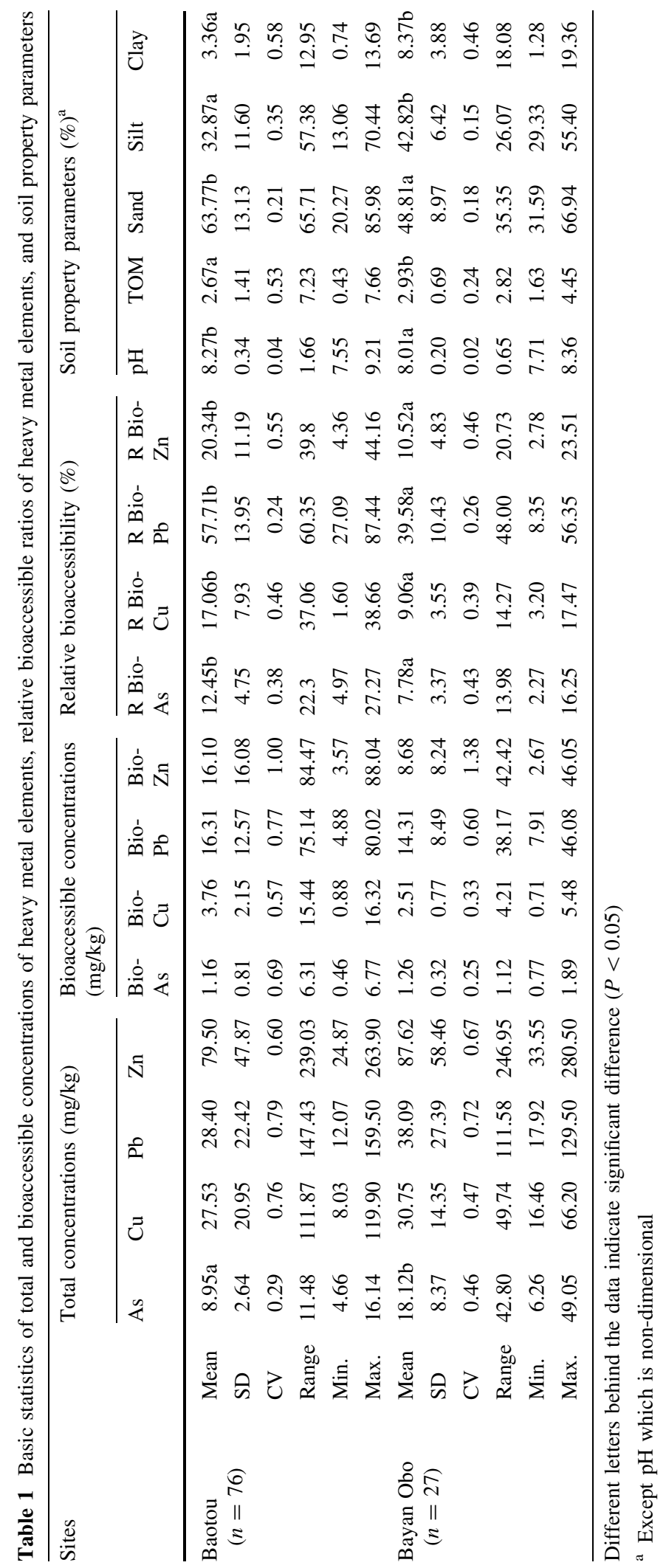



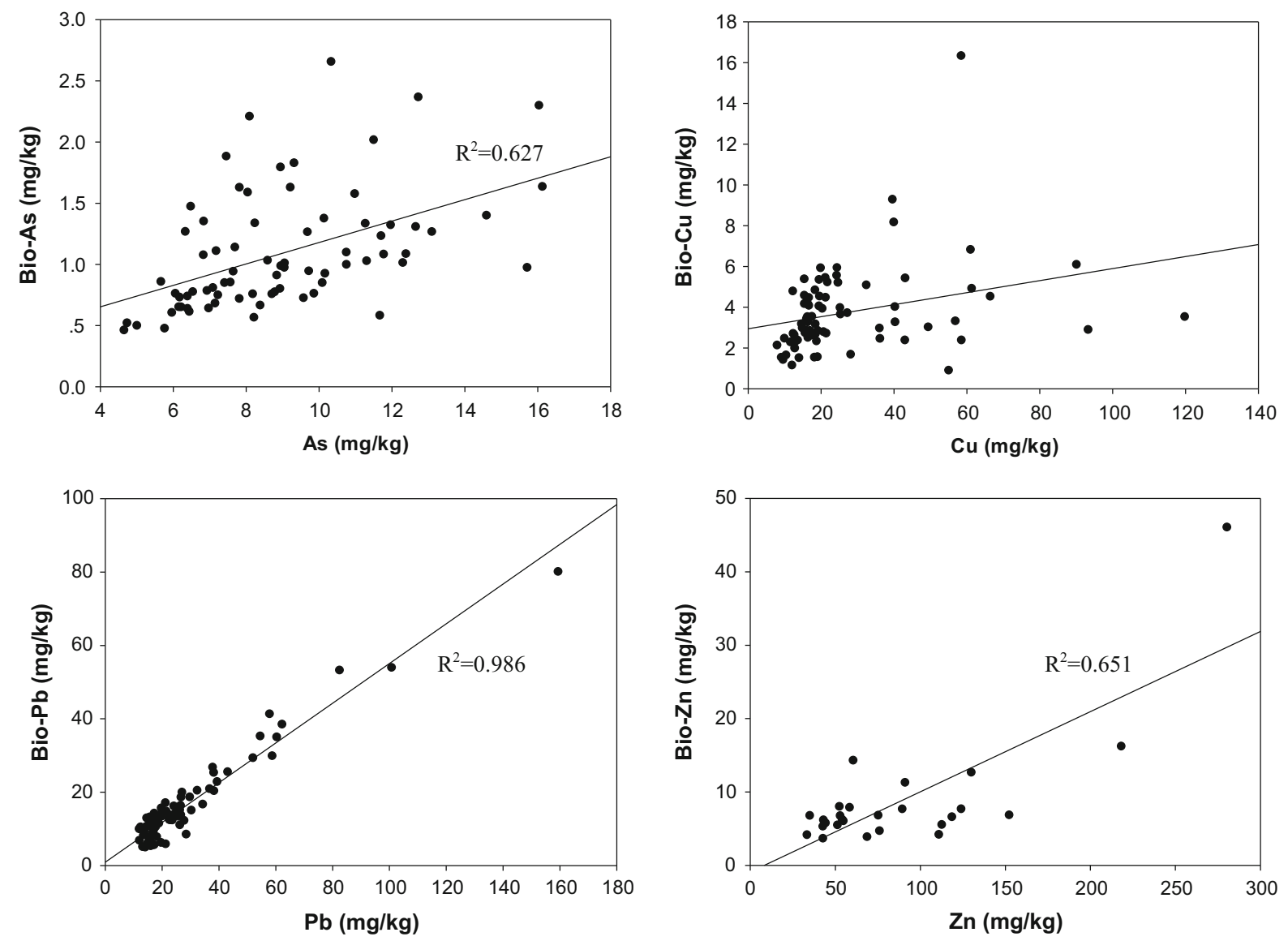

Fig. 2 Relationship between the bioaccessible and total arsenic, copper, lead, and zinc concentrations in the soils of Baotou

models contained the T-HMs variable. An As model was only developed for Baotou and included $\mathrm{pH}$ as the main factor. The $\mathrm{Cu}$ model in Baotou contained silt and sand variables, but the $\mathrm{Cu}$ model developed for Bayan Obo contained no soil property parameters. The $\mathrm{Pb}$ model for Baotou contained a silt variable, but the model developed for Bayan Obo included TOM and clay variables instead. The $\mathrm{Zn}$ model for Baotou contained clay and silt variables, but no soil property parameters were included in the $\mathrm{Zn}$ model for Bayan Obo (Table 2). The prediction models for Bio-HMs clearly differed between these two adjacent areas. It is notable that soil property parameters that had high variations were more often included in these models. For instance, SD, CV, and the sand and silt variables tended to be larger at the Baotou site than at Bayan Obo; consequently, the $\mathrm{Cu}$, $\mathrm{Pb}$, and $\mathrm{Zn}$ prediction models for Baotou contained one or two of these variables. However, the Bayan Obo models entirely excluded these variables.

\section{Discussion}

Bio-HM models for Baotou and Bayan Obo differed; there were more soil property variables included in the Baotou models than in the Bayan Obo models (Table 2). These results indicate that a common predictive model could not be established for these two adjacent areas. The development of predictive models for soil Bio-HMs is an active area of study because of the importance of regulating HM bioavailability. However, universal models for Bio-HMs have not yet been identified (Caboche et al. 2010; Römkens et al. 2009; Rodrigues et al. 2013). Although Baotou and Bayan Obo are geographically quite close, these sites differ in their geological backgrounds. Bayan Obo is in a Fe-REE mineral belt and therefore had a higher baseline of various HMs, likely located in the inner crystals of minerals. Baotou is highly affected by smelting activities, and its soil has elevated levels of HMs that are likely to be more bioaccessible when 

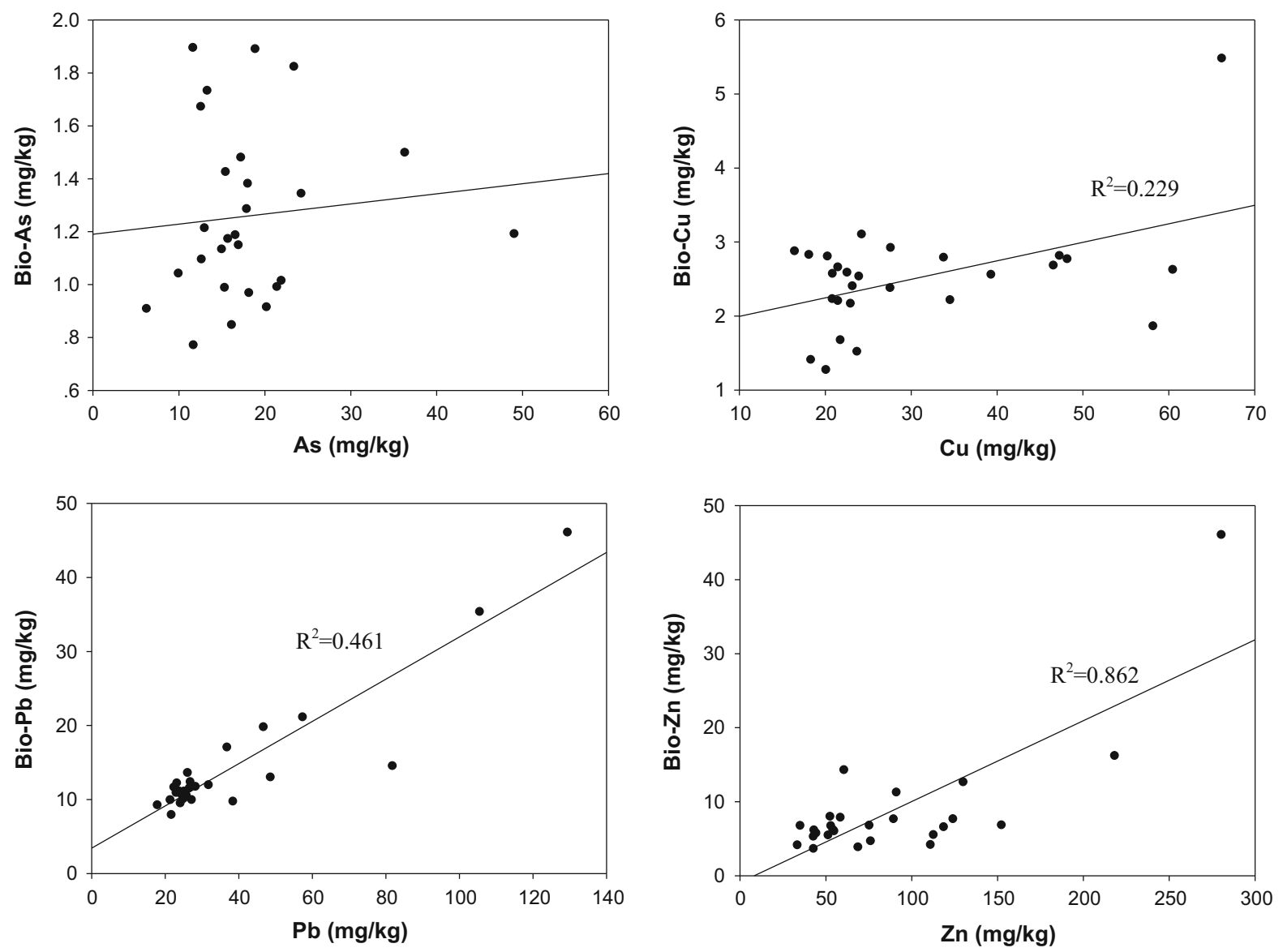

Fig. 3 Relationship between the bioaccessible and total arsenic, copper, lead, and zinc concentrations in the soils of Bayan Obo

Table 2 Linear regression coefficients and $R^{2}$ values of respective equations for bioaccessibility concentrations of HMs

\begin{tabular}{|c|c|c|c|c|c|c|c|c|c|}
\hline & Interc. & $\log (\mathrm{HM})$ & $\mathrm{pH}^{\mathrm{a}}$ & $\log (\%$ TOM $)$ & $\log$ (\% clay) & $\log (\%$ silt $)$ & $\log (\%$ sand $)$ & $R^{2}$ & Sig. \\
\hline \multicolumn{10}{|c|}{ Baotou $(n=76)$} \\
\hline As & -1.907 & 0.896 & 0.130 & $\mathrm{x}$ & $\mathrm{x}$ & $\mathrm{x}$ & $\mathrm{x}$ & 0.441 & 0.05 \\
\hline $\mathrm{Cu}$ & -3.731 & 0.174 & $\mathrm{x}$ & $\mathrm{x}$ & $\mathrm{x}$ & 1.232 & 1.215 & 0.260 & 0.05 \\
\hline $\mathrm{Pb}$ & -2.675 & 0.969 & $\mathrm{x}$ & $\mathrm{x}$ & $\mathrm{x}$ & 0.567 & 0.903 & 0.870 & 0.01 \\
\hline $\mathrm{Zn}$ & 0.894 & 1.027 & $\mathrm{x}$ & $\mathrm{x}$ & 0.591 & -1.325 & $\mathrm{x}$ & 0.566 & 0.05 \\
\hline \multicolumn{10}{|c|}{ Bayan Obo $(n=27)$} \\
\hline As & $\mathrm{x}$ & $\mathrm{x}$ & $\mathrm{x}$ & $\mathrm{x}$ & $\mathrm{x}$ & $\mathrm{x}$ & $\mathrm{x}$ & $\mathrm{x}$ & $\mathrm{x}$ \\
\hline $\mathrm{Cu}$ & -0.012 & 0.273 & $\mathrm{x}$ & $\mathrm{x}$ & $\mathrm{x}$ & $\mathrm{x}$ & $\mathrm{x}$ & 0.153 & 0.05 \\
\hline $\mathrm{Pb}$ & 0.312 & 0.472 & $\mathrm{x}$ & 0.486 & -0.157 & $\mathrm{x}$ & $\mathrm{x}$ & 0.925 & 0.05 \\
\hline $\mathrm{Zn}$ & -0.624 & 0.796 & $\mathrm{x}$ & $\mathrm{x}$ & $\mathrm{x}$ & $\mathrm{x}$ & $\mathrm{x}$ & 0.596 & 0.05 \\
\hline
\end{tabular}

All data were $\log _{10}$-transformed before regression analysis, except $\mathrm{pH}$ value; $\mathrm{x}$, excluded variables in linear regressions

compared to that of Bayan Obo (Zhu et al. 2015). This geological difference may explain why a common predictive model was not obtained for these two adjacent areas. This finding is in accordance with Caboche et al. (2010), who reported that the soil edaphic properties $(\mathrm{pH}, \mathrm{CEC}$, and clay or organic 
matter content) of two French sites contaminated by different anthropogenic activities (Villemagne mine in Southern France and MetalEurop Nord smelter in Northern France) could not be used to model $\mathrm{Pb}$ bioaccessibility; soil edaphic properties differed slightly between these two sites and, thus, a single model failed to robustly predict $\mathrm{Pb}$ bioaccessibility in both sites (Caboche et al. 2010).

Among the parameters measured, soil texture was the best predictor of Bio-HMs in Baotou (except in the As model). Our Bio-As findings are in agreement with those of Silva et al. 2014 who suggested that As mobility is independent of the granulometric fractions of the examined soil profiles (Sauvé et al. 2000). The predictors used in the models of Bio- $\mathrm{Cu}$, Bio- $\mathrm{Pb}$, and Bio-Zn, however, were inconsistent with previous studies, which found $\mathrm{pH}$ to be the best predictor (Buchter et al. 1989; Rieuwerts et al. 1998, 2006; Rodrigues et al. 2013). This difference may be because Bio-HMs are highly dependent on the variation of specific soil properties and not their absolute values. In this study, $\mathrm{pH}$ varied in ranges by 1.66 in Baotou and 0.65 in Bayan Obo. Both of these values were much lower than those in Rieuwerts's study ( $\mathrm{pH}$ varied by 2.8) (Rieuwerts et al. 2006) and those in Rodrigues's study (pH varied by 3.9) (Rodrigues et al. 2013, 2010). The ranges of TOM, sand, silt, and clay percentages in Baotou are 7.23, 65.71, 57.38, and 12.95, respectively, which are larger than the values of 2.82, 35.35, 26.07, and 18.08 in Bayan Obo (except for clay). The larger deviations in the soil properties of Baotou compared with Bayan Obo can also been observed in the SD and CV data (Table 1), which may also have substantial effects on Bio-HMs. This finding may explain why soil property parameters were included in the Baotou models but not in the Bayan Obo models (with the exception of the $\mathrm{Pb}$ model) (Table 2).

\section{Conclusion}

In summary, the utilization of existing databases of soil HMs and soil properties is a practical method to predict Bio-HMs. However, there is still much to be learned. Variability in soil properties shapes predictive models. When there is little variation of soil properties, these properties are not included as variables in the predictive model. This finding is illustrated by the results of the Bio-HMs models for Bayan Obo, which changed only with total HMs concentrations. However, when one or more soil properties experienced a large amount of variation in a given area, these parameters would be included in the models and play pivotal roles in predicting Bio-HMs, as illustrated by our findings in Baotou. A common predictive model of Bio-HMs using total HMs concentrations and soil property parameters has not been established in these two adjacent areas, primarily because Baotou and Bayan Obo have distinct geological backgrounds.

Acknowledgments This work was supported by the Key Project of the Knowledge Innovation Program of IGSNRR (2012ZD002) and the National Science and Technology Support Program in the 12th Five-Year Plan of China (2012BAJ24B03). We thank Dr. Nan Zhang and Mr. Kai Fan for their assistance with field sampling.

\section{References}

Buchter, B., Davidoff, B., Amacher, M., Hinz, C., Iskandar, I., \& Selim, H. (1989). Correlation of Freundlich Kd and n retention parameters with soils and elements. Soil Science, 148, 370-379.

Caboche, J., Denys, S., Feidt, C., Delalain, P., Tack, K., \& Rychen, G. (2010). Modelling Pb bioaccessibility in soils contaminated by mining and smelting activities. Journal of Environmental Science and Health, Part A: Toxic/Hazardous Substances and Environmental Engineering, 45, 1264-1274.

Drew, L. J., Qingrun, M., \& Weijun, S. (1990). The Bayan Obo Iron rare-earth niobium deposits, inner-Mongolia, China. Lithos, 26, 43-65.

Drexler, J. W., \& Brattin, W. J. (2007). An in vitro procedure for estimation of lead relative bioavailability: With validation. Human and Ecological Risk Assessment, 13, 383-401.

Ettler, V., Vitkova, M., Mihaljevic, M., Sebek, O., Klementova, M., Veselovsky, F., et al. (2014). Dust from Zambian smelters: Mineralogy and contaminant bioaccessibility. Environmental Geochemistry and Health, 36, 919-933.

Fu, S., \& Wei, C. Y. (2013). Multivariate and spatial analysis of heavy metal sources and variations in a large old antimony mine, China. Journal of Soils and Sediments, 13, 106-116.

Hu, Y. N., Liu, X. P., Bai, J. M., Shih, K. M., Zeng, E. Y., \& Cheng, H. F. (2013). Assessing heavy metal pollution in the surface soils of a region that had undergone three decades of intense industrialization and urbanization. Environmental Science and Pollution Research, 20, 6150-6159.

Juhasz, A. L., Smith, E., Weber, J., Rees, M., Rofe, A., Kuchel, T., et al. (2007). Comparison of in vivo and in vitro methodologies for the assessment of arsenic bioavailability in contaminated soils. Chemosphere, 69, 961-966.

Kim, J. Y., Kim, K. W., Lee, J. U., Lee, J. S., \& Cook, J. (2002). Assessment of As and heavy metal contamination in the vicinity of Duckum Au-Ag mine, Korea. Environmental Geochemistry and Health, 24, 213-225. 
Madrid, F., Biasioli, M., \& Ajmone-Marsan, F. (2008). Availability and bioaccessibility of metals in fine particles of some urban soils. Archives of Environmental Contamination and Toxicology, 55, 21-32.

Nelson, D. W., \& Sommers, L. E. (1982). Total carbon, organic carbon, and organic matter (pp. 539-579). Madison, Wisconsin: American Society of Agronomy.

Oomen, A. G., Rompelberg, C. J., Bruil, M. A., Dobbe, C. J., Pereboom, D. P., \& Sips, A. J. (2003). Development of an in vitro digestion model for estimating the bioaccessibility of soil contaminants. Archives of Environmental Contamination and Toxicology, 44, 281-287.

Pelfrene, A., Waterlot, C., Mazzuca, M., Nisse, C., Bidar, G., \& Douay, F. (2011). Assessing Cd, Pb, Zn human bioaccessibility in smelter-contaminated agricultural topsoils (northern France). Environmental Geochemistry and Health, 33, 477-493.

Pelfrene, A., Waterlot, C., Mazzuca, M., Nisse, C., Cuny, D., Richard, A., et al. (2012). Bioaccessibility of trace elements as affected by soil parameters in smelter-contaminated agricultural soils: A statistical modeling approach. Environmental Pollution, 160, 130-138.

Rieuwerts, J. S., Ashmore, M. R., Farago, M. E., \& Thornton, I. (2006). The influence of soil characteristics on the extractability of $\mathrm{Cd}, \mathrm{Pb}$ and $\mathrm{Zn}$ in upland and moorland soils. The Science of the Total Environment, 366, 864-875.

Rieuwerts, J., Thornton, I., Farago, M., \& Ashmore, M. (1998). Quantifying the influence of soil properties on the solubility of metals by predictive modelling of secondary data. Chemical Speciation and Bioavailability, 10, 83-94.

Rodrigues, S. M., Cruz, N., Coelho, C., Henriques, B., Carvalho, L., Duarte, A. C., et al. (2013). Risk assessment for $\mathrm{Cd}, \mathrm{Cu}$, $\mathrm{Pb}$ and $\mathrm{Zn}$ in urban soils: Chemical availability as the central concept. Environmental Pollution, 183, 234-242.

Rodrigues, S. M., Henriques, B., Ferreira da Silva, E., Pereira, M. E., Duarte, A. C., \& Romkens, P. F. (2010). Evaluation of an approach for the characterization of reactive and available pools of twenty potentially toxic elements in soils: Part I-the role of key soil properties in the variation of contaminants' reactivity. Chemosphere, 81, 1549-1559.

Römkens, P. F., Guo, H. Y., Chu, C. L., Liu, T. S., Chiang, C. F., \& Koopmans, G. F. (2009). Characterization of soil heavy metal pools in paddy fields in Taiwan: Chemical extraction and solid-solution partitioning. Journal of Soils and Sediments, 9, 216-228.

Ruby, M., Schoof, R., Brattin, W., Goldade, M., Post, G., Harnois, M., et al. (1999). Advances in evaluating the oral bioavailability of inorganics in soil for use in human health risk assessment. Environmental Science and Technology, 33, 3697-3705.

Sauvé, S., Hendershot, W., \& Allen, H. E. (2000). Solid-solution partitioning of metals in contaminated soils: Dependence on $\mathrm{pH}$, total metal burden, and organic matter. Environmental Science and Technology, 34, 1125-1131.

Silva, V., Loredo, J., Fernandez-Martinez, R., Larios, R., Ordonez, A., Gomez, B., et al. (2014). Arsenic partitioning among particle-size fractions of mine wastes and stream sediments from cinnabar mining districts. Environmental Geochemistry and Health, 36, 831-843.

Wei, C. Y., Wang, C., \& Yang, L. S. (2009). Characterizing spatial distribution and sources of heavy metals in the soils from mining-smelting activities in Shuikoushan, Hunan Province, China. Journal of Environmental Sciences-China, 21, 1230-1236.

Wei, B. G., \& Yang, L. S. (2010). A review of heavy metal contaminations in urban soils, urban road dusts and agricultural soils from China. Microchemical Journal, 94, 99-107.

Zhu, Y. G. (2012). Environmental impacts of rapid urbanization in China: A showcase of recent research developments. Environmental Science and Pollution Research, 19, 1351.

Zhu, X. D., Wei, C. Y., Yang, F. (2015). The baselines of heavy metals in Baotou and Bayan Obo and its application in evaluation of heavy metal contamination. Journal of Natural Resources (in Chinese), 30, (in press). 